\title{
MBTI® Type and Interprofessional Communication in Doctor of Physical Therapy Students
}

\author{
Laura J. Smith \\ University of Michigan Flint, johlaur@umflint.edu \\ Christin P. Curtis \\ University of Michigan-Flint, chrcurti@umflint.edu \\ Morgan Perry \\ University of Michigan-Flint, mogan@umich.edu \\ Laura LoVasco \\ South University, lovascol@aol.com \\ Amy M. Yorke \\ University of Michigan-Flint, amyorke@umflint.edu \\ See next page for additional authors
}

Follow this and additional works at: https://nsuworks.nova.edu/ijahsp

Part of the Medicine and Health Sciences Commons

\section{Recommended Citation}

Smith LJ, Curtis CP, Perry M, LoVasco L, Yorke AM, Talley SA. MBTI® Type and Interprofessional Communication in Doctor of Physical Therapy Students. The Internet Journal of Allied Health Sciences and Practice. 2019 Jan 01;17(4), Article 9.

This Manuscript is brought to you for free and open access by the College of Health Care Sciences at NSUWorks. It has been accepted for inclusion in Internet Journal of Allied Health Sciences and Practice by an authorized editor of NSUWorks. For more information, please contact nsuworks@nova.edu. 


\title{
MBTI® Type and Interprofessional Communication in Doctor of Physical Therapy Students
}

\begin{abstract}
Purpose: Interprofessional education (IPE) improves patient outcomes and health care by use of appropriate communication. Personality factors may affect communication in interprofessional collaborations. The purposes of this study were to identify common Meyers-Briggs Type Indicator ${ }^{\circledR}$ $(\mathrm{MBTI})$ personality types of entry-level Doctor of Physical Therapy students along with gender difference and to make recommendations as to how the $\mathrm{MBTI}{ }^{\circledR}$ assessment can used to help develop the interprofessional communication competency domain among student physical therapists. Method: Thirtytwo entry-level Doctor of Physical Therapy students in the first semester of their third year of study completed the paper based, MBTI ${ }^{\circledR}$ Form M Self-Scorable. Results: Most personality types were represented; the most common were ISTJ $(n=5)$ and ENFJ $(n=4)$. Significant gender differences were found in the Introversion/Extraversion and the Thinking/Feeling dichotomies, but no differences were found related to age. Conclusions and Recommendations: The MBTI® may be an effective tool for students to engage in self-evaluation and improve awareness of how personality types may influence communication and teamwork in IPE activities, thereby incorporating this into deliberate behavioral changes. Recommendations for integrating these findings into classroom teaching styles includes: 1) fostering tools and techniques for communication in interprofessional teams 2) deliberate practice in provider-patient interactions, and 3) self-reflection and practice.
\end{abstract}

\section{Author Bio(s)}

Dr. Laura Smith is an Assistant Professor and is the Associate Director for Post-Professional Clinical Professional Development at the University of Michigan-Flint. She has extensive teaching experience in entry-level and post-professional education. Her research interests are in musculoskeletal performance measures and interprofessional education/practice.

\section{Authors}

Laura J. Smith, Christin P. Curtis, Morgan Perry, Laura LoVasco, Amy M. Yorke, and Susan A. Talley 


\title{
1IJAHSP \\ The Internet Joutnal of Allied Health Sciences and Practice
}

Dedicated to allied health professional practice and education

Vol. 17 No. 4 ISSN 1540-580X

\section{MBT ${ }^{\circledR}$ and Interprofessional Communication in Doctor of Physical Therapy Students}

\author{
Laura J. Smith 1 \\ Christin P. Curtis ${ }^{1}$ \\ Morgan Perry ${ }^{1}$ \\ Laura LoVasco ${ }^{2}$ \\ Amy M. Yorke ${ }^{1}$ \\ Susan A. Talley ${ }^{1}$
}

1. University of Michigan Flint

2. South University

United States

\begin{abstract}
Purpose: Interprofessional education (IPE) improves patient outcomes and health care by use of appropriate communication. Personality factors may affect communication in interprofessional collaborations. The purposes of this study were to identify common Meyers-Briggs Type Indicator@ (MBTI@) personality types of entry-level Doctor of Physical Therapy students along with gender difference and to make recommendations as to how the MBTI囚 assessment can used to help develop the interprofessional communication competency domain among student physical therapists. Method: Thirty-two entry-level Doctor of Physical Therapy students in the first semester of their third year of study completed the paper based, MBTI@ Form M Self-Scorable. Results: Most personality types were represented; the most common were ISTJ $(n=5)$ and ENFJ $(n=4)$. Significant gender differences were found in the Introversion/Extraversion and the Thinking/Feeling dichotomies, but no differences were found related to age. Conclusions and Recommendations: The MBTIß may be an effective tool for students to engage in self-evaluation and improve awareness of how personality types may influence communication and teamwork in IPE activities, thereby incorporating this into deliberate behavioral changes. Recommendations for integrating these findings into classroom teaching styles includes: 1) fostering tools and techniques for communication in interprofessional teams 2) deliberate practice in provider-patient interactions, and 3) selfreflection and practice.
\end{abstract}

Keywords: health care students, collaboration, personality 


\section{INTRODUCTION}

This paper explores common personality types among Doctor of Physical Therapy students (SPTs) and the potential impacts that personality types may have upon the interprofessional education (IPE) learning domains of communication and teamwork. IPE is defined as students learning about, from, and with each other by means of deliberate practice to create effective collaborative healthcare practices that will improve patient outcomes and the health care system. ${ }^{1-2}$ Six interprofessional learning domains as defined by the World Health Organization can be summarized as teamwork, roles and responsibilities, communication, learning and critical reflection, relationship with and recognizing the needs of the patient, and ethical practice. ${ }^{1}$ Communication is also a core competency domain as outlined by the Interprofessional Education Collaborative (IPEC); the other three IPEC competencies include values/ethics, roles/responsibilities, and teams and teamwork for interprofessional practice. ${ }^{2}$ The goals of IPEC's core competencies are to provide a foundation for IPE learning so that it can be recognized and required as a common element of health professional programs by accrediting bodies. ${ }^{2}$ Effective January 1, 2018 the Commission on Accreditation in Physical Therapy Education (CAPTE) requires interprofessional education in all accredited entry-level physical therapy programs. ${ }^{3}$ With communication being emphasized among all three entities, including Doctor of Physical Therapy (DPT) curricular content that emphasizes teamwork and communication will enhance IPE.

The four interprofessional competency domains are community and population-oriented as well as patient and family-centered and together create a learning continuum in IPE development and lifelong learning trajectory. ${ }^{2}$ The interprofessional communication competency is the ability to, "...communicate with patients, families, communities, and professionals in health and other fields in a responsive and responsible manner that supports a team approach to the promotion and maintenance of health and the prevention and treatment of disease."2 This competency is further divided into eight sub-competencies, five of which relate to how one communicates with others based on personality preferences. ${ }^{2}$ Five of the communication sub-competencies that correlate with personality type were selected for this study:

CC1. Choose effective communication tools and techniques, including information systems and communication technologies, to facilitate discussions and interactions that enhance team function.

CC2. Communicate information with patients, families, community members, and health team members in a form that is understandable, avoiding discipline-specific terminology when possible.

CC4. Listen actively, and encourage ideas and opinions of other team members.

CC6. Use respectful language appropriate for a given difficult situation, crucial conversation, or conflict.

CC7. Recognize how one's uniqueness (experience level, expertise, culture, power, and hierarchy within the health team) contributes to effective communication, conflict resolution, and positive interprofessional working relationships. ${ }^{2}$

Personality factors were identified as a key factor preventing collaboration in a study of interprofessional collaboration among 4 occupational therapists and 4 registered nurses. ${ }^{4}$ Personality types influenced attitudes towards teamwork and the development of rapport and mutual respect, which affected communication while providing care in teams. ${ }^{4}$ However, only a few published articles offer information on personality types of healthcare students and their influences on ability to master the IPE domains, namely communication.

The Meyers-Briggs Type Indicator $(M B T \mid 囚)$ is a self-report inventory based on Jung's theory of psychological types that is used to assess personality preferences or personality types. The poles include Extraversion (E)/Introversion (I), Sensing (S) /Intuition $(N)$, Thinking (T) /Feeling (F), and Judging (J)/Perceiving (P). Extraverts tend to be focused on the outer world, whereas introverts tend to be focused on the inner ideas and impressions. Sensing refers to those who tend to be focused on the present and concrete information, whereas intuition refers to those who prefer focusing on the future and towards patterns and possibilities. Those who fall into the thinking type tend to base decisions on logic and objective analysis of cause and effect, whereas those who fall into the feeling type tend to base decisions on values and subjective evaluation of person-centered concerns. Judging type refers to those who tend to like planned and organized approach with things settled, whereas perceiving refers to those who tend to enjoy flexible and spontaneous approaches and keeping their options open. ${ }^{5}$

MBTI@ personality types have been related to learning styles, professional leadership roles, and clinical success, yet the relationship to interprofessional communication skills is not well established.6-8 Since patient-provider communication impacts patient care outcomes and many patient complaints stem from communication rather than medical competency, it behooves educators to explore factors that may influence communication skills, such as the MBTI®.9-10

The relationship between the MBTI $囚$ and academic success commonly measured by grade point average and didactic learning has been explored in physical therapy, general medicine, general college populations, and concordant teacher-student 
personalities with mixed results. ${ }^{11-14} \mathrm{~A}$ void exists in the literature on the potential value of the MBTI@ related to interprofessional education in physical therapy students. Therefore, the primary purpose of this study is to identify common MBTI $B$ personality types of entry-level SPTs as well as gender differences. A secondary objective is to make recommendations as to how the MBTI® assessment may be used to help develop the interprofessional communication competency domain among physical therapy students.

\section{METHODS \\ Subjects}

Participants were 32 entry-level SPTs in the first semester of their third year of study at a master's larger level public teaching institution in the United States. All participants were 18 years of age or older and were informed of the risks and benefits of participation in the study before signing the informed consent. Prior to recruitment, the Institutional Review Board of the University of Michigan-Flint approved this study.

\section{Instrumentation - MBTI® Form M Self-Scorable}

The paper based, MBTI@ Form M Self-Scorable instrument was administered by a certified MBTI® practitioner using standardized instructions. ${ }^{5}$ The MBTI ${ }^{2}$ Form M consists of 93 items and employs a self-report forced-choice questionnaire..$^{5}$

\section{Research Design and Procedures}

Data was collected via face-to-face interaction. Each participant completed the Self-Scorable paper Form M of the MBTIß in one sitting. Participants received a $\$ 10$ incentive after completing the MBTI@.

\section{Statistical Analysis}

Responses on the MBTI尺 are used to compute a numerical score to establish each individual's preference for each pole. The four pole preferences are used to identify a 4-letter type for personality, with 16 possible personality types. ${ }^{5}$ Frequencies of the MBTI@ scores were reported to describe the proportion of participants that scored in each of the 4 dichotomous personality type categories. The frequency of MBTIß types for each gender was assessed using cross-tabulation to assess any significant differences. The Statistical Package for the Social Sciences was used (SPSS Inc., Chicago, Illinois) for all analyses.

\section{RESULTS}

In this exploratory study, 32 SPTs participated (17 female, 53.1\%). The participants ranged from 23 to 31 years of age (mean 25.2 +1.8). Table 1 reports the distribution of personality types. Significantly more females tended towards Extraversion (71\%) and Thinking (76\%) while males tended towards Introversion (73\%) and Feeling (67\%) ( $p=0.01$, Tables 2 and 3). There were no significant differences between males and females in Intuitive/Sensing and Perceiving/Judging ( $p>0.05)$ (Tables 4 and 5$)$ nor any significant associations between age and personality type (Table 6).

Table 1. MBTI® Personality Types

\begin{tabular}{|l|c|c|c|}
\hline \multicolumn{1}{|c|}{ MBTIR Type } & $\begin{array}{c}\text { Female } \\
\boldsymbol{n}(\%)\end{array}$ & $\begin{array}{c}\text { Male } \\
\boldsymbol{n}(\%)\end{array}$ & $\begin{array}{c}\text { TOTAL } \\
\boldsymbol{n}(\%)\end{array}$ \\
\hline ENFJ & $4(23.5)$ & - & $4(12.5)$ \\
\hline ENFP & $2(11.8)$ & $1(6.7)$ & $3(9.4)$ \\
\hline ENTJ & - & $1(6.7)$ & $1(3.1)$ \\
\hline ENTP & - & $1(6.7)$ & $1(3.1)$ \\
\hline ESFJ & $1(5.9)$ & $1(6.7)$ & $2(6.3)$ \\
\hline ESFP & $2(11.8)$ & - & $2(6.3)$ \\
\hline ESTJ & $3(17.6)$ & - & $3(9.4)$ \\
\hline ESTP & - & - & - \\
\hline INFJ & $1(5.9)$ & - & $2(3.1)$ \\
\hline INFP & $1(5.9)$ & $1(6.7)$ & $1(3.1)$ \\
\hline INTJ & - & $1(6.7)$ & $2(6.3)$ \\
\hline INTP & - & $2(13.3)$ & $3(9.4)$ \\
\hline ISFJ & $2(11.8)$ & $1(6.7)$ & $1(3.1)$ \\
\hline ISFP & - & $1(6.7)$ & $5(15.6)$ \\
\hline ISTJ & $1(5.9)$ & $4(26.7)$ & \\
\hline
\end{tabular}




\begin{tabular}{|c|c|c|c|}
\hline ISTP & - & $1(6.7)$ & $1(3.1)$ \\
\hline TOTAL & $17(100)$ & $15(100)$ & $32(100)$ \\
\hline
\end{tabular}

${ }^{*} E=$ Extraverted, $I=$ Introverted, $S=$ Sensing, $N=$ Intuitive, $F=$ Feeling, $T=$ Thinking, $J=$ Judging, $P=$ Perceiving

Table 2. MBTI® Extraversion/Introversion \& Gender

\begin{tabular}{|l|c|c|c|}
\hline & $\begin{array}{c}\text { Extraversion } \\
\boldsymbol{n}(\boldsymbol{\%})\end{array}$ & $\begin{array}{c}\text { Introversion } \\
\boldsymbol{n}(\%)\end{array}$ & $\begin{array}{c}\text { TOTAL } \\
\boldsymbol{n}(\%)\end{array}$ \\
\hline Male & $4(27)$ & $11(73)$ & $15(100)$ \\
\hline Female & $12(71)$ & $5(29)$ & $17(100)$ \\
\hline \multicolumn{1}{|c|}{ TOTAL } & $16(50)$ & $16(50)$ & $32(100)$ \\
\hline
\end{tabular}

$p=0.01$

Table 3. MBTI® Intuitive/Sensing \& Gender

\begin{tabular}{|l|c|c|c|}
\hline & $\begin{array}{c}\text { Intuitive } \\
\boldsymbol{n}(\%)\end{array}$ & $\begin{array}{c}\text { Sensing } \\
\boldsymbol{n}(\%)\end{array}$ & $\begin{array}{c}\text { TOTAL } \\
\boldsymbol{n}(\%)\end{array}$ \\
\hline Male & $7(47)$ & $8(53)$ & $15(100)$ \\
\hline Female & $8(47)$ & $9(53)$ & $17(100)$ \\
\hline \multicolumn{1}{|c|}{ TOTAL } & $15(47)$ & $17(53)$ & $32(100)$ \\
\hline
\end{tabular}

$p=0.98$

Table 4. MBTI@ Thinking/Feeling \& Gender

\begin{tabular}{|l|c|c|c|}
\hline & $\begin{array}{c}\text { Thinking } \\
\boldsymbol{n}(\%)\end{array}$ & $\begin{array}{c}\text { Feeling } \\
\boldsymbol{n}(\%)\end{array}$ & $\begin{array}{c}\text { TOTAL } \\
\boldsymbol{n}(\%)\end{array}$ \\
\hline Male & $5(33)$ & $10(67)$ & $15(100)$ \\
\hline Female & $13(76)$ & $4(24)$ & $17(100)$ \\
\hline \multicolumn{1}{|c|}{ TOTAL } & $18(56)$ & $14(44)$ & $32(100)$ \\
\hline
\end{tabular}

$p=0.01$

Table 5. MBTI@ Perceiving/Judging \& Gender

\begin{tabular}{|l|c|c|c|}
\hline & $\begin{array}{c}\text { Perceiving } \\
\boldsymbol{n}(\%)\end{array}$ & $\begin{array}{c}\text { Judging } \\
\boldsymbol{n}(\%)\end{array}$ & $\begin{array}{c}\text { TOTAL } \\
\boldsymbol{n}(\%)\end{array}$ \\
\hline Male & $8(53)$ & $7(47)$ & $15(100)$ \\
\hline Female & $12(71)$ & $5(29)$ & $17(100)$ \\
\hline \multicolumn{1}{|c|}{ TOTAL } & $20(62)$ & $12(38)$ & $32(100)$ \\
\hline
\end{tabular}

$p=0.31$

Table 6. MBTI® Dichotomies \& Age

\begin{tabular}{|l|c|c|c|}
\hline Dichotomous Type & Mean age (years) & t-value & p-value \\
\hline Extraverted $(E)$ & 24.8 & -1.544 & 0.13 \\
\hline Introverted $(I)$ & 25.7 & & 0.52 \\
\hline Intuitive $(N)$ & 25.0 & -0.656 & \\
\hline Sensing $(S)$ & 25.4 & & 0.23 \\
\hline Thinking $(T)$ & 25.6 & 1.215 & 0.78 \\
\hline Feeling $(F)$ & 24.9 & & \\
\hline Perceiving (P) & 25.3 & 0.282 & \\
\hline Judging $(J)$ & 25.2 & & \\
\hline
\end{tabular}




\section{DISCUSSION}

The majority of the 16 personality types identified by the MBTI@ were widely distributed among the 32 participants with the most common personality type represented as ISTJ $(n=5,15.6 \%)$, closely followed by ENFJ $(n=4,12.5 \%)$. All eight personality poles were represented by at least 1 participant. The diversity of personality types in this small sample emphasizes the need for SPTs to be aware of characteristics of personality types and how those traits may affect interprofessional communication during IPE. For example, it is possible that working with a professional of similar preferences could hinder effective communication just as easily as someone of a very different preference. Students who understand the wide distribution of preference types may have better strategies for interprofessional communication as compared to those who do not value differences.

The majority of the participants in this study were females $(53 \%)$ which is slightly lower than the overall mean of CAPTE accredited physical therapy programs where females represent $62 \%$ of the student body. ${ }^{15}$ In this study, females favored Extraversion and Thinking while males favored Introversion and Feeling. This is inconsistent with past research that men in a physical therapy program tended toward Thinking type. ${ }^{11}$ There were no significant differences between genders and Judging/Perceiving type in this study, which is inconsistent with Stith and Norton who found that women tended towards Judging. This difference between this study and Stith and Norton may be related to the small sample sizes of both studies. ${ }^{11}$

Exploration of MBTI@ personality types and SPTs has previously been reported in the literature. . $^{6} 16-17$ One study examined MBTI@ personality types in relation to classroom group participation and the other studies focused on personality distributions among various health professional students. $6,16-17$ Among a sample of 17 students enrolled in a professional physical therapy program, students who identified as Extraverted were more vocal and more likely to have dialogue with group members before agreeing on answers to questions when compared to Introverted types. ${ }^{6}$ The sample had nearly an equal amount of MBTI® Extraversion preference $(n=9)$ as Introversion preference $(n=8)$, which is similar to the results of the present study as the same number of participants preferred Extraversion and Introversion ( $\mathrm{n}=16$ each).

\section{Recommendation 1: Fostering Tools and Techniques for Communication}

There have been mixed results on whether MBTI $\mathbb{R}$ personality types are connected to clinical and professional success. One study noted that those falling in the Extraverted group tended to have better clinical performance and interaction with patients. ${ }^{8}$ Another study found that personality type was not related to clinical performance among a group of undergraduate medical students. ${ }^{18}$ With varying results presented in other literature, it may be helpful to further understand how personality types may influence successful interactions in care settings, particularly in interprofessional contexts. In the current study, there was nearly an equal preference for Intuitive/Sensing. Past research has shown that people with a Sensing preference perform better with objective measures whereas people with an Intuitive preference prefer theoretical constructs. ${ }^{16}$ These preferences may be used when teaching IPE content to SPTs, as nearly equal numbers prefer Sensing to Intuition. An example of both objective and theoretical constructs used in IPE during physical therapy education would be use of laymen's terms for communicating with a patient; listing medical versus laymen's terms represents the Sensing preference whereas discussion about the patient's educational level impacting understanding the information represents the Intuitive preference.

With a range of learning experiences in clinical education and the professional realm, students must strengthen their ability to use other personality types to meet realistic expectations of course work and professional practice..$^{19} \mathrm{It}$ is suggested that classroom teaching styles be tailored to a variety of personality types that call for learning experiences beyond the dominant types. ${ }^{20}$ Learning experiences for all students need to foster an environment where students can learn to mold to different personality traits for various situations. Use of the best personality trait can then be applied to critical thinking, problem solving, and technical skills in a variety of tasks in clinical settings that may require interprofessional communication skills outside of one's normal personality style. ${ }^{20-}$ ${ }^{21}$ Selecting a better personality trait may mean understanding how one's own personality preferences may influence communication in these situations and employing tools and techniques to effectively communicate outside of one's preferred style for better clinical success. This represents a more realistic, dynamic professional environment than a static one and relates to IPEC sub-competency CC1 which includes communication tools and techniques that positively impact discussions, interactions, and team function. ${ }^{2}$

Fostering learning environments and hands-on interprofessional experiences are particularly important for situations in which students must act in a way not necessarily in concordance with their personality type. ${ }^{14}$ For example, when working in an interprofessional team, collaboration was hindered when differences arose among professional knowledge, lack of respect, and personality differences. ${ }^{4}$ Working together to set common aims among health professions students may draw them to collaboration rather than competition, promoting practice and reflection, a supportive infrastructure, and multiple methods of communication to serve patients. ${ }^{22}$ 
In reference to MBTI 1 personality types, a Judging type may prefer an organized schedule to patient care or meetings. ${ }^{5}$ Working in interprofessional and team-based care models may require more flexibility, which may be preferred by Perceiving types. Engaging in self-reflection and being aware of personal preferences may be beneficial to students so they can strengthen their abilities to work among a myriad of clinical and professional demands. Therefore, MBTI@ personality types should be explored in context with realities of clinical demands and communication performance.

One model that has incorporated the idea that communication styles impact health outcomes in patients is situation, background, assessment, recommendation (SBAR). ${ }^{23}$ This model considers that different professions are taught to communicate differently based on the situation at hand and their professional needs, creating possible barriers to collaboration and communication. Using SBAR considers and incorporates personality, professional, and situational differences (barriers) to promote effective communication and patient outcomes through applying a common "critical language" for urgent situations and patient care. Entertaining models like SBAR may be helpful in considering the importance of and means by which personality can be included into health professions education.

\section{Recommendation 2: Deliberate Practice in Provider - Patient Interactions}

Interprofessional communication skills extend beyond the team of health providers and includes the patients and families as well. The IPEC sub-competency CC2 provides the framework for a needed skill of health providers - the ability to communicate with an individual at their level, rather than the discipline-specific professional level. ${ }^{2}$ In a previous study of medical graduates, the results from their MBTI $\circledast$ personality distribution varied greatly from the distribution among the general population. ${ }^{10}$ The graduates tended to have a higher preference for Intuitive/Perceiving and Thinking/Judgement as compared to the adult norm. ${ }^{10} \mathrm{It}$ was suggested that this may create the potential for miscommunication between physician and patient due to different preferences regarding mode of perception and that when taking personality types into account during interactions with patients, the potential points for miscommunication may be lessened.10 An Extrovert/Intuitive type may try to explain too much of the theoretical aspects of a disease or how an exercise benefits the patients, thus creating a barrier between the physical therapist and the patient. Teaching a student who falls into this personality type to use less theory and more laymen's terms will assist in providing better communication with a patient.

Intentional learning activities that deliberately place students in hands-on and practical learning experiences that may not be concordant with their personality type can give them the opportunity to develop related skills. Consideration of the personality type and gender distributions may assist health professional educators to develop learning environments to best foster interprofessional skills, particularly communication in clinical settings. Therefore, this may be valuable for IPE training to use an assessment tool, such as the MBTIQ, to help students prepare for the interprofessional communication they will face when working in diverse teams and with a wide range of patients. Engaging in these behaviors may affect attitudes towards and abilities to work in situations that are discordant with personality type and psychological preferences. This is related to IPEC sub-competency CC2, which speaks to enhancing communication in a way that works across disciplines (in interprofessional teams) and with those beyond the realm of health care professionals (such as patients, family members, and the community). ${ }^{2}$ Teaching a student who identifies with the Introvert personality type to practice becoming assertive in an urgent situation during laboratory time will assist this student in future clinical practice. SPTs need to be ready to communicate in an appropriate manner for all types of situations that they will face during patient care and within interdisciplinary teams.

Essential communication skills have been outlined as a guide to better interaction with patients, family members, and the community. For example, one outline of essential communication skills includes opening the discussion, gathering information, understanding the patient's perspective, sharing information, reaching an agreement on problems and plans, and providing closure. ${ }^{24}$ Relatedly, the most common provider to patient communication barriers are that physicians do not thoroughly listen to or care about their issues, or provide too little information about their treatment. ${ }^{25}$ These same complaints would likely be similar to those among other health care providers. Essential communication skills are not fostered solely through experience; rather, these must be specifically enhanced through self-awareness and promoting understanding the needs of others. This requires selfawareness, sensitivity, and reflection on both the faculty and students' parts. ${ }^{24}$ Being aware of one's own personality and how this may impact how one interacts and communicates with others (health professionals and those beyond the health professional realm) is vital to promoting effective collaboration and care. Considering how personality influences interactions could possibly assist in overcoming these barriers to communication in IPE through self-reflection and guided practice. 


\section{Recommendation 3: Self-Reflection and Practice}

Knowing one's own MBTIB personality type allows students to acknowledge their personal strengths and to begin to develop the ability to work outside of their preference in situations that demand doing so. ${ }^{14}$ Additionally, personality factors have been found to be key factors in preventing or enhancing collaboration, particularly communication, during interprofessional collaboration. ${ }^{4}$ In a study of occupational therapists and registered nurses, personality types affected the teamwork and communication amongst team members. ${ }^{4}$ This indicates that consideration of personality in interprofessional contexts is vital. Applying MBTI@ personality types in learning contexts may enhance a health professions student's ability to work with non-concordant personality types and possibly enhance communication skills during interprofessional care experiences.

Self-complexity is understanding one's own involvedness as a person, including past experiences and group identities amongst diversity. ${ }^{26}$ For IPEC's CC7, this is the first step in seeing the ways in which individual factors like identity, professional role, and personality factors impact communication. ${ }^{2}$ Professional role is an identity that requires reflection; including how past experiences influence behaviors in clinical settings, how other group identities influence care, and differences between in self-perception versus others' context of role identity. In one study, communication and role understanding were the two most important factors in positive patient and provider outcomes. ${ }^{27}$ By considering one's own role as well as acknowledging and respecting others' roles, communication may be strengthened. ${ }^{27}$ How one engages within these situations may be reflective of personality type and related psychological preferences.

Further, applying metacognitive abilities involves reflecting on someone's thoughts and engaging in self-reflection on how these thoughts affect responses and actions in context. ${ }^{26}$ Through honest self-reflection, one can begin to draw ties between personality type and the ways to engage in communication within diverse professional groups and with patients, drawing self-reflection into enhancing interactions. Cognitive reframing can help to reorient responses that may not always be in concordance with - personality type. Cognitive reframing incorporates the idea that behaviors may be easier to change than attitudes and tendencies. ${ }^{26}$ By being aware of personality type and psychological tendencies, deliberately engaging in interprofessional contexts that may not be concordant with one's personality type may develop flexibility in responses to being in a group, thus promoting professional and clinical success. This deliberate practice may enhance communication through honest self-reflection and related intentional behavior changes.

\section{Future Considerations}

As stated by the IPE core competencies, effective communication is a necessary part of competent collaboration between healthcare professions. ${ }^{2}$ Improvement in communication between disciplines is a common benefit of IPE experiences. ${ }^{28-31}$ Personality traits may impact communication in interprofessional settings and collaborative practices. Since interprofessional education may foster skills related to interdisciplinary collaboration, understanding and incorporating personality traits into the educational methods and learning opportunities may benefit future health professionals and should be explored.

During IPE, effective communication tools and techniques may be developed and refined over time. Tools and techniques that require development would be dependent on one's own personality type as well as the types of those with which one must interact. Different constructs that impact communication include listening, giving and receiving feedback, sharing information effectively, common language, and dealing with conflict. ${ }^{2}$ Specifically, being able to recognize and understand the uniqueness of team members (including oneself) and hierarchies in the team may promote more effective interprofessional communication. ${ }^{2}$ As IPE continues to become more prevalent in health professions accrediting bodies, it may be valuable to explore the personality types of health professions students, especially as it relates to communication, as a way to enhance the IPE learning experiences. Additionally, bringing attention to the variety of personality types that may be involved within interprofessional team collaboration and patient-provider interactions may reveal ways to make communication more successful.

\section{Limitations}

This study has some limitations. Although the MBTI® personality type of participants in this study was diversified, these findings should be interpreted with caution due to the small sample size and the standard deviation of age of the subjects. Additionally, this study did not assess fostering skills in interprofessional settings according to MBTI@ personality type but rather is based in theory and suggestions from interprofessional education entities. Future studies should assess this in an interprofessional setting to confirm its benefit.

\section{CONCLUSION}

In conclusion, results of this study showed a wide range of personality types in third year student physical therapists, as determined by the MBTI@. Overall, student physical therapists tended to prefer Thinking or Perceiving rather than Feeling or Judging, 
respectively, but almost equally prefer Extraverted or Intuitive as Introverted or Sensing. Gender differences were found, as females tended towards Extraverted and Thinking preferences. There were no significant differences between age and personality type, though this may be a result of small standard deviation for age in this study. Since professional and clinical environments may demand one to work outside their own psychological preferences, especially during times of stress or growth such as during clinical education, providing students with the opportunity to learn about their own personality types and psychological preferences can promote self-awareness and areas for growth. ${ }^{14}$ Nonetheless, variable personality should be taken into account as it may affect how SPTs learn, choose, and implement interprofessional communication.

\section{References}

1. World Health Organization. Framework for action on interprofessional education and collaborative practice. http://www.who.int/hrh/resources/framework_action/en/. Accessed November 15, 2017.

2. Interprofessional Education Collaborative. Core competencies for interprofessional collaborative practice: 2016 update. https://www.ipecollaborative.org/resources.html. Accessed December 10, 2017.

3. Commission on Accreditation in Physical Therapy Education. Standards and required elements for accreditation of Physical Therapist education programs. http://www.capteonline.org/AccreditationHandbook/. Accessed December 7, 2017.

4. Loy B, Micheff H, Nguyen K, O'Brien V. Interprofessional Collaboration Between Occupational Therapists and Nurses in an Acute Care Setting: An Exploratory Study [master's thesis]. San Rafael, CA: Dominican University of California; 2015.

5. Myers I. Introduction to Type: A Guide to Understanding Your Results on the MBTI ${ }^{\circledR}$ Assessment. 7th ed. Sunnyvale, CA: CPP, Inc.; 2016.

6. Chesbro SB. Becoming Adult Learners: Student Learning in a Dual-Campus Physical Therapy Program using Distance Education [dissertation]. Oklahoma City, OK: Oklahoma State University; 2000.

7. Rovezzi-Carroll S, Leavitt R. Personality characteristics and expressed career choice of graduating physical therapy students. Phys Ther. 1984;64(10): 1549-1552. [PMID:6483986]

8. von Bergmann H, Dalrymple KR, Shuler CF. Personality preference distribution of dental students admitted to one dental school using different selection methods. J Dent Educ. 2013;78(4): 580-588. [PMID: 24706688]

9. Street RL, Makoul G, Arora NK, Epstein RM. How does communication heal? Pathways linking clinician-patient communication to health outcomes. Patient Educ Couns. 2009;74(3):295-301. [PMID:19150199]

10. Clack GB, Allen J, Cooper D, Head JO. Personality differences between doctors and their patients: implications for the teaching of communication skills. Med Educ. 2004;38(2), 177-186. [PMID: 14871388]

11. Stith JS, Norton BJ. Prediction of academic performance in physical therapy by the Myers-Briggs Type Indicator, need for cognition survey, and pre-enrollment measures. Phys Ther, 79(5), S49.

12. Prasad M. Application of Myers-Briggs Type Indicator in health professions: a literature review. Asian J Manage. 2016;7(4):297-306.

13. Harasym PH, Leong EJ, Juschka BB, Lucier GE, Lorscheider FL. Myers-Briggs psychological type and achievement in anatomy and physiology. Am J Physiol. 1995;268(6 Pt 3):S61-S65. [PMID: 7598175]

14. Renner $W$, Gaball $C$, Ramalingam $P$. The importance of individual differences in students and teachers and their interaction with culture: Jung's personality types. J Indian Acad of Appl Psychol. 2014;40(2):177-184.

15. Commission on Accreditation in Physical Therapy Education. Aggregate program data, 2016-2017 Physical Therapist education programs fact sheets. http://www.capteonline.org/AggregateProgramDatal. Accessed November 3, 2016.

16. Hardigan PC, Cohen SR. A comparison of learning styles among seven health professions: Implications for optometric education. Internet J Allied Health Sci Pract. 2003;1(1), 1-7.

17. Hardigan PC, Cohen SR. A comparison of osteopathic, pharmacy, physical therapy, physician assistant, and occupational therapy students' personality styles: Implications for education and practice. J Pharm Teach. 1999;7(2):67-79.

( The Internet Journal of Allied Health Sciences and Practice, 2019 
18. Murthy KS, O'Neill PA, Byrne GJ. The influence of learning styles and personality profiles on undergraduate medical students' clinical performance. Med Teach. 2013;35(7):608-609. [PMID:23600670]

19. French G, Cosgriff T, Brown T. Learning style preferences of Australian occupational therapy students. Aust Occup Ther J. 2007;54:S58-S65.

20. Williams B, Brown T, Etherington J. Learning style preferences of undergraduate pharmacy students. Curr Pharm Teach Learn. 2013;5(2):110-119.

21. Huston JL, Huston TL. How learning style and personality type can affect performance. Health Care Superv. 1995;13(4):3845. [PMID: 10142541]

22. McPherson K, Headrick I, Moss F. Working and learning together: good quality care depends on it, but how can we achieve it? Qual Health Care. 2001;10(Suppl 2):ii46-ii53. [PMID: 11700379]

23. Leonard M, Graham S, Bonacum D. The human factor: the critical importance of effective teamwork and communication in providing safe care. Qual Saf Health Care. 2004;13(suppl 1):i85-i90. [PMID:15465961]

24. Haq C, Steele DJ, Marchand L, Seibert C, Brody D. Integrating the art and science of medical practice: innovations in teaching medical communication skills. Fam Med. 2004;36(Suppl):S43-50. [PMID: 14961402]

25. Levinson W, Lesser CS, Epstein RM. Developing physician communication skills for patient-centered care. Health Aff. 2010;29(7):1310-1318. [PMID:20606179]

26. Dreachslin JL, Gilber MJ, Malone B. Diversity and cultural competence in health care: A systems approach. 1st ed. New York: John Wiley \& Sons; 2012.

27. Suter E, Arndt J, Arthur N, Parboosingh J, Taylor E, Deutschlander S. Role understanding and effective communication as core competencies for collaborative practice. J Interprof Care. 2009;23(1):41-51. [PMID:19142782]

28. Bridges DR, Abel MS, Carlson J, Tomkowiak J. Service learning in interprofessional education: a case study. J Phys Ther Educ. 2010;24(1):44-49.

29. Barnett GV, Hollister L, Hall S. Use of standardized patient to clarify interdisciplinary team roles. Clin Simul Nurs.

2011;7(5):e169-e173.

30. King J, Beanlands S, Fiset V, Chartrand L, Clarke S, Findlay T, et al. Using interprofessional simulation to improve collaborative competences for nursing, physiotherapy, and respiratory therapy students. J Interprof Care. 2016; 30(5):599-605. [PMID: 27340933]

31. Luctkar-Flude M, Hopkins-Rosseel D, Jones-Hiscock C, Pulling C, Gauthier J, Knapp A, et al. Interprofessional infection control education using standardized patients for nursing, medical and physiotherapy students. J Interprof Ed Pract. 2016;2:2531.

32. Nisbet G, Hendry GD, Rolls G, Field MJ. Interprofessional learning for pre-qualification health care students: An outcomesbased evaluation. J Interprof Care. 2008;22(1):57-68. [PMID: 18202986]

33. von der Lancken S, Levenhagen K. Interprofessional teaching project with nursing and physical therapy students to promote caregiver and patient safety. J Nurs Ed. 2014;53(12):704-709. [PMID: 25494193] 